\title{
Preface: Emerging trends in aquatic ecology III
}

\author{
Sidinei Magela Thomaz $($ D - Luigi Naselli-Flores $(\mathbb{D})$ Diego Fontaneto $($ D \\ Koen Martens
}

Published online: 9 March 2020

(C) Springer Nature Switzerland AG 2020

Humans have never faced such major threats to their homes as they are experiencing now. Despite several global initiatives to ameliorate environmental problems, to preserve biodiversity and to alleviate poverty, these major threats are far from being resolved. According to a recent survey conducted by Ripple et al. (2017) and signed by 15,364 scientists of 184 countries, several indicators of environmental health are still worsening significantly. For example, along with the continuing increase of atmospheric $\mathrm{CO}_{2}$ and global temperatures (the threats best known by the general public as "climate change"), there are still steep increases in atmospheric concentrations of

Guest editors: Koen Martens, Sidinei M. Thomaz, Diego Fontaneto \& Luigi Naselli-Flores / Emerging Trends in Aquatic Ecology III

\section{S. M. Thomaz ( $\square)$}

Universidade Estadual de Maringá, DBI/PEA/Nupélia, Maringá, PR, Brazil

e-mail: smthomaz@nupelia.uem.br

L. Naselli-Flores

Department of Biological, Chemical and Pharmaceutical

Sciences and Technologies, University of Palermo,

Palermo, Italy

e-mail: luigi.naselli@unipa.it

D. Fontaneto

Water Research Institute, National Research Council of

Italy, Verbania Pallanza, Italy

e-mail: diego.fontaneto@cnr.it methane and nitrous oxide, in ocean acidification and in the number of regions affected by dead zones, all at global scales, to cite only some examples. Aquatic (both marine and freshwater) and terrestrial ecosystems and their biodiversity are also declining at a planetary scale, with no signs of imminent recovery, ever since extensive surveys started back in the 1970s (WWF, 2018).

There is no doubt that these global tendencies are most worrying and require urgent action by all: scientists, politicians and the general public at large. However, there are also more regional and localized examples of positive scenarios, which could lead us to be optimistic. For example, while the planet index values are still declining in the Neotropical and IndoPacific regions, they are nearly constant in the

\author{
K. Martens \\ Royal Belgian Institute of Natural Sciences, OD Nature, \\ Freshwater Biology, Brussels, Belgium \\ e-mail: Koen.Martens@naturalsciences.be \\ K. Martens \\ Department of Biology, University of Ghent, Ghent, \\ Belgium
}


Palaearctic Region and even show small signs of recovery in the Nearctic Region (see Fig. 22 in the WWF Report, 2018). Similarly, there are signs that some tropical biomes, such as the Atlantic Forest (a biodiversity hotspot in Brazil), which includes large river basins whose waters are vital for both humans and for biodiversity conservation, have recovered large areas during the last decade (Resende et al., 2018; Crouzeilles et al., 2019). Such positive examples were possible because part of human society became aware of the importance of environmental and climatic issues and of the need for biodiversity conservation. However, such societal efforts would be nullified without the scientific knowledge which provides ever increasing evidence on the importance of environmental health for the well-being of humans (the "One-Health" concept) and which offers the tools necessary to improve environmental quality and to enable ecosystems restoration.

Within this context, we are proud of the important role Hydrobiologia has played in publishing novel science on the ecology and evolution of aquatic ecosystems since it was created in 1948. Our journal publishes papers dealing with all types of aquatic ecosystems, both inland and marine, located on every continent. The scientists who use Hydrobiologia as the outlet of their investigations have a wide geographical distribution and the same is true for our readership, which truly makes it the "International Aquatic Library". For all of these reasons, we are confident that the scientific results published by Hydrobiologia help identifying AND solving problems in aquatic ecosystems, wherever they are still required. In a world where science denial is an unfortunate reality and represents a real threat to society (e.g. Hansson, 2017; Schmid \& Betsch, 2019), making good science available to a wide public is more than ever an absolute necessity.

In this spirit, the editors of Hydrobiologia started in 2015 to organize the present series on "Emerging Trends in Aquatic Ecology" (Martens, 2015; NaselliFlores et al., 2017), which herewith arrives at its third volume. The special issues of this series are organized by Hydrobiologia editors and at least one of the authors of each paper is a Hydrobiologia editor. In this way, our editors are directly involved in writing about emerging trends and issues on aquatic sciences, attracting the attention of a wide and international audience. We hope our readers will enjoy reading the papers of this special issue and, mainly, that these investigations improve our knowledge, inspire young scientists and help solving problems related to emerging issues in aquatic ecosystems.

The present issue "Emerging Trends in Aquatic Ecology III" holds 14 papers focusing on a variety of methodologies, research themes and questions, and groups of organisms. However, the present issue in the "Emerging Trends" series continues to present novel approaches in aquatic sciences, as did the previous ones, there is one important difference with volume two, in that this set of papers comprises also examples from marine sciences.

Four papers in this issue deal with aquatic invasive species, one of the greatest threats to aquatic biodiversity and ecosystem services. Flood et al. (2020) conducted a systematic review, focusing on the impacts of invasive species on aquatic ecosystem functioning and services. The authors identified ecosystem and geographic bias in the literature which focused on ecosystem functions: freshwater received far more attention than marine ecosystems, and Europe and North America have been much more studied than any of the other continents. There is also a bias toward the type of ecosystem function, with primary and secondary production, along with nutrient cycling, composing $80 \%$ of the studies. Flood et al. (2020) found that few studies addressed ecosystem services as such. Also, the majority of studies which claim to study ecosystem functioning actually investigated ecosystem structure, while many studies investigated proxies instead of real functions. Some specific functions (e.g. bioturbation, decay rate and biomagnification), the assessment of multiple functional metrics and the links between ecosystem function and services, were poorly investigated by aquatic ecologists. These are the research gaps identified by this review.

Adey \& Larson (2020) investigated an interesting challenge in ecology, namely the relation between experimental and field results. Using stable isotopes, they tested the hypothesis that the dominance of the invasive crayfish Faxonius rusticus (Girard, 1852) in laboratory assays was related to its trophic position in the field. They found no relation between the dominance of $F$. rusticus in the laboratory and the field diet or function of this species. Results did not depend on methods used (acclimation time, timing of primary consumer collection and tissue analysed) or 
stable isotope analyses. The authors conclude that at least for this invasive species, it is difficult to connect results obtained in the field to those from the lab, using this approach.

Braga et al. (2020) conducted an experiment in mesocosms to investigate if invasive species impacts on native communities and ecosystem functions are related to synergistic, antagonistic or additive interactions between invasive species. Impacts were identified at the population, community and ecosystem levels and they were indeed explained by additive effects. This finding did not support the invasional meltdown hypothesis, which predicts synergistic effects of invasive species on native communities. However, the lack of antagonistic effects, along with the predominance of additive effects, indicates that the increasing number of invasive species worldwide may enhance the impacts on native communities and ecosystem functions.

Biotic resistance and propagule pressure are two important determinants of invasive species success. Louback-Franco et al. (2020) tested these two hypotheses simultaneously in experiments and in the field for the highly invasive submerged species Hydrilla verticillata (L.f.) Royle. The experiment showed that the success of this invasive species increases with propagule pressure at the same rate, regardless of the presence or absence of the native isoetid-like macrophyte Helanthium tenellum (Mart. ex Schult. f.), also showing that this species is not able to resist invasion. The experimental findings were corroborated by long-term data obtained in a reservoir, where $H$. tenellum was substituted by $H$. verticillata in the majority of sites.

These four papers highlight, in different ways, direct and indirect threats that invasive species pose to biodiversity conservation. Another type of direct threat to biodiversity conservation was evaluated by Brotherton et al. (2020), who conducted an extensive literature review to assess the offtake of fish and birds from wetlands. They found several reasons to be concerned about this widely used practice. Firstly, data are not reported in a consistent way, global datasets are very limited (especially for water birds), and the lack of data is more critical for developing countries, where biodiversity is generally higher. Secondly, hidden offtake (e.g. through illegal methods of subsistence, recreational or sport fishing) makes that official statistics are underestimates. Thirdly, there are few examples of sustainable offtake for fish and water birds in the literature. Lately, the risk posed by offtake may be enhanced by the isolated nature of wetlands. The authors conclude that there is an urgent need for accurate assessments of offtake at a global scale, which would be a first step towards the conservation of species threatened by offtake in wetlands.

Two papers investigate non-marine ostracods. Schön \& Martens (2020) assessed which abiotic and biotic variables are related to infections of non-marine ostracods by the Cardinium bacteria. Infections were influenced by reproductive mode, being found only in ostracods with mixed and asexual reproduction, and occurring to a greater degree in females. Infections also increased toward higher latitudes, likely in association to the phenomenon known as geographic parthenogenesis. By comparing infection of different ostracod lineages, the authors concluded that ancient asexual darwinulid ostracods (which are less infected) probably lost endosymbiosis during their long evolutionary history, while ostracods with mixed reproduction probably have had infections more recently. They also suggest that Cardinium is probably not the only cause of parthenogenesis in non-marine ostracods, because there was no complete fixation in all asexual lineages.

Da Conceição et al. (2020) applied Ecological Niche Modelling to a large-scale dataset to estimate the potential distribution of non-marine ostracods in one of the most species-rich regions of the world: South America. The distribution of the majority of groups was predicted mainly by the minimum temperatures of the coldest month and the mean elevation of the locality. Specific groups of ostracods were also well predicted by order of the river (which is a proxy of the aquatic ecosystem size) and rainfall during the wettest month. The modelling exercise indicated that there are several regions and basins in South America which are propitious to be colonized by ostracod species which are not still there, including non-native species. This finding is a cause of concern owing to the threat of invasive species to native diversity.

Bacterial communities colonizing different substrates of a lake were investigated by Eckert et al. (2020). The authors used molecular tools to test a series of hypotheses related to the diversity and similarity of these communities among different substrates: the effects of two water depths, the 
association with daphnids and copepods, with bottom sediments and with stones. Specialist taxa dominated the lake community and each micro-habitat had a specific bacterial community, but the same habitat had highly similar communities in different sampling stations. According to the authors, differences are potentially maintained by environmental filters. Sediments had a higher biodiversity and the bacteria composition of this compartment differed from all others which were investigated. In contrast, daphnids and copepods shared similar bacterial composition and similar communities occurred at the two water depths. Finally, the authors found beta diversity was mainly driven by nestedness, since the communities in less diverse habitats were sub-sets of the sediment community. Thus, this compartment can be considered as a "seed bank" for freshwater microbes.

Gomes-dos-Santos et al. (2020) revised the literature about genomics of the highly diverse phylum Mollusca, analysing the trends of the scientific publications on this group in recent decades. The most commonly used research methods were Restriction site Associated DNA, mitogenomes, transcriptomes and whole genomes. Studies using these approaches increased between 2009 and 2019. Gastropods and bivalves are the most studied groups, while cephalopods and other mollusc lineages received far less attention. However, compared to many other metazoans (e.g. vertebrates, arthropods and nematodes), mollusc genomics are still under-investigated, although admittedly, some other groups of invertebrates have never had their genomes investigated. The number of molluscan genome assemblies found on NCBI is very low and the phylogeny and evolution of this group are still poorly investigated by genomic approaches. The authors state that the improvement of the understanding of various evolutionary and adaptive aspects of Mollusca will depend of the increased use of high-throughput sequencing (HTS) in the near future. The enhancement of studies employing omics and the use of new techniques, which are some of the gaps found by this review, are essential considering the biodiversity, socio-economic and ecological importance of this group.

Switching the reproduction strategy from an asexual to a sexual mode is an important adaptation observed in several species. In a population ecology study, Haltiner et al. (2020) conducted an experiment to test whether Daphnia galeata Sars 1863 switched its reproductive mode in response to population size, while at the same time keeping food availability controlled. Reproduction of D. galeata switched from asexual to sexual reproduction at high population densities and this did not depend on increased competition for resources. Thus, differently from other species, which may require several simultaneous cues to change reproduction modes, the present experiment shows that crowding is a sufficient cue for D. galeata. According to the authors, large populations are associated with higher infection rates and, thus, the change in reproduction mode is likely a strategy to escape from parasites.

Two papers dealt with benthic communities in contrasting environments: one study on tropical streams and another on Antarctica. Invertebrates in highly biodiverse tropical streams located in the Atlantic Forest hotspot (Brazil) were investigated with regard to their niche breadth by Serpa et al. (2020). Sampling leaf patches, they described the habitat preferences of invertebrate shredders, considering physical, chemical and biological attributes as explanatory variables. Shredders colonized almost all leaf patches, this in spite of great differences between them. The environmental conditions associated with shredders varied conspicuously and shredder taxa presented very different niche breadths and habitat requirements. The authors infer that the high diversity in the Atlantic Forest results from the formation of leaf patches with different characteristics, which in turn may favour the high diversity of shredder taxa they found. Owing to differences in niche breadths and habitat requirements, the shredder species recorded could complement each other in the leaf-processing in this investigated stream.

Piazza et al. (2020) employed photogrammetric techniques and adaptive cluster sampling, repeated at different sampling stations over time, to simulate a pilot study and evaluate the efficiency of protocols to sample mega benthos taxa in coastal communities of Antarctic. This type of study is urgently needed, owing to the necessity to understand environmental changes on this continent, as it is the most sensitive to global warming. In addition to finding distributional patterns for some taxa which differ from the ones previously described, the authors also showed that systematic sampling using $0.0625 \mathrm{~m}^{2}$ quadrants produced the highest accuracy. An important conclusion from this study was that the investigations conducted previously 
with benthos in this region might be biased, because they mainly used $1 \mathrm{~m}^{2}$ plot size. This information should be taken into consideration to increase the confidence of future monitoring of Antarctic coastal zones.

Two papers focused on ecosystem perspectives of aquatic environments, namely one on carbon stock and one on light pollution. Lima et al. (2020) investigated the environmental factors which affect the carbon stock in temperate intertidal seagrass meadows. These communities have the potential to contribute to climate change mitigation and thus it is important to understand their capacity to store carbon. Elevation, along with a group of sediment features (e.g. density, sorting coefficient, proportion of mud, pore water $\mathrm{pH}$, sulphates and alkalinity), were the most important determinants of sediment $\mathrm{C}$ stocks. The authors show that seagrass meadows colonizing sediments with high proportion of mud and low bulk density are the ones with the greatest capacity to store carbon. Finally, they state that temperate meadows differ considerably in their capacity to stock $\mathrm{C}$, which is higher in meadows located in habitats near sheltered harbours, where the sediment has high mud content and more sorted particles.

The increased threat generated by light pollution has been studied mainly in the last decade. The effects of artificial light at night (ALAN) on temporal variability of autotrophic biofilm biomass and photosynthesis were assessed by Maggi et al. (2020) on rocks at the Mediterranean shore. Light pollution with LED lamps did not change the temporal variability of the microphytobenthos biomass, but it enhanced the temporal variability of the maximum photosynthetic efficiency during the colonization and mature stages of microphytobenthos communities. These changes were probably related to adjustments to light pollution by groups of species which show synchronous or asynchronous larger temporal fluctuations of their maximum photosynthetic efficiency, along with greater possibility of extinction of some species and changes in species relative abundances. In contrast, the temporal variability of biomass did not change in response to ALAN. Effects of ALAN were in general weaker at the beginning of rock colonization because grazers had an opposite effect of the one caused by light. The main conclusion of the authors is that artificial light influences different microphytobenthos species either directly because of their light sensitivity or indirectly via grazer activity.

The editors of the present special issue hope that you will enjoy reading the present set of papers and are already looking forward to producing the fourth issue in the series of "Emerging Trends in Aquatic Ecology".

\section{References}

Adey, A. K. \& E. R. Larson, 2020. Dominance and diet are unrelated within a population of invasive crayfish. Hydrobiologia. https://doi.org/10.1007/s10750-01904088-x.

Braga, R. R., V. M. Ribeiro, A. A. Padial, S. M. Thomaz, I. P. Affonso, J. Wojciechowski, L. G. S. Ribas, E. R. da Cunha, V. G. Tiburcio \& J. R. S. Vitule, 2020. Invasional meltdown: an experimental test and a framework to distinguish synergistic, additive, and antagonistic effects. Hydrobiologia. https://doi.org/10.1007/s10750-01904107-x.

Brotherton, S., C. B. Joyce \& J. P. W. Scharlemann, 2020. Global offtake of wild animals from wetlands: critical issues for fish and birds. Hydrobiologia. https://doi.org/10. 1007/s10750-020-04188-z.

Crouzeilles, R., E. Santiami, M. Rosa, L. Pugliese, P. H. S. Brancalion, R. R. Rodrigues, J. P. Metzger, M. Calmon, C. A. Scaramuzza, M. H. Matsumoto, A. Padovezi, R. B. Benini, R. B. Chaves, T. Metzker, R. B. Fernandes, F. R. Scarano, J. Schmitt, G. Lui, P. Christ, R. M. Vieira, M. M. D. Senta, G. A. Malaguti, B. B. N. Strassburg \& S. Pinto, 2019. There is hope for achieving ambitious Atlantic Forest restoration commitments. Perspectives in Ecology and Conservation 17: 80-83.

da Conceição, E. O., T. Mantovano, R. de Campos, T. F. Rangel, K. Martens, D. Bailly \& J. Higuti, 2020. Mapping the observed and modelled intracontinental distribution of non-marine ostracods from South America. Hydrobiologia. https://doi.org/10.1007/s10750-019-04136-6.

Eckert, E. M., S. Amalfitano, A. Di Cesare, C. Manzari, G. Corno \& D. Fontaneto, 2020. Different substrates within a lake harbour connected but specialised microbial communities. Hydrobiologia. https://doi.org/10.1007/s10750019-04068-1.

Flood, P., A. Duran, M. Barton, A. M. Molina and J. C. Trexler. 2020. Invasion impacts on functions and services of aquatic ecosystems. Hydrobiologia.

Gomes dos Santos, A., M. Lopes-Lima, L. F. C. Castro \& E. Froufe, 2020. Molluscan genomics: the road so far and the way forward. Hydrobiologia. https://doi.org/10.1007/ s10750-019-04111-1.

Haltiner, L., C. Hänggi, P. Spaak \& S. R. Dennis, 2020. Sex in crowded places: population density regulates reproductive strategy. Hydrobiologia. https://doi.org/10.1007/s10750019-04143-7. 
Hansson, S. O., 2017. Science denial as a form of pseudoscience. Studies in History and Philosophy of Science 63: 39-47.

Lima, M. A. C., R. D. Ward \& C. B. Joyce, 2020. Environmental drivers of sediment carbon storage in temperate seagrass meadows. Hydrobiologia. https://doi.org/10.1007/s10750019-04153-5.

Louback-Franco, N., M. Dainez-Filho, D. C. Souza \& S. M. Thomaz, 2020. A native species does not prevent the colonization success of an introduced submerged macrophyte, even at low propagule pressure. Hydrobiologia. https://doi.org/10.1007/s10750-019-04116-w.

Maggi, E., I. Bertocci \& L. Benedetti-Cecchi, 2020. Light pollution enhances temporal variability of photosynthetic activity in mature and developing biofilm. Hydrobiologia. https://doi.org/10.1007/s10750-019-04102-2.

Martens, K., 2015. Preface: emerging trends in aquatic ecology. Hydrobiologia 750: 1-4.

Naselli-Flores, L., K. Martens, D. Fontaneto \& S. Magela Thomaz, 2017. Preface: emerging trends in aquatic ecology II. Hydrobiologia 800: 1-5.

Piazza, P., S. A. Gattone, A. Guzzi \& S. Schiaparelli, 2020. Towards a robust baseline for long-term monitoring of Antarctic coastal benthos. Hydrobiologia. https://doi.org/ 10.1007/s10750-020-04177-2.

Resende, C. L., F. R. Scarano, E. D. Assad, C. A. Joly, J. P. Metzger, B. B. N. Strassburg, M. Tabarelli, G. A. Fonseca \& R. A. Mittermeier, 2018. From hotspot to hopespot: an opportunity for the Brazilian Atlantic Forest. Perspectives in Ecology and Conservation 16: 208-214.

Ripple, W. J., C. Wolf, T. M. Newsome, M. Galetti, M. Alamgir, E. Crist, M. I. Mahmoud, W. F. Laurance and 15,364 scientist signatories from 184 countries, 2017. World scientists' warning to humanity: A second notice. BioScience 67:1026-1028.

Schmid, P. \& C. Betsch, 2019. Effective strategies for rebutting science denialism in public discussions. Nature Human Behavior 3: 931-939. https://doi.org/10.1038/s41562-0190632-4.

Schön, I. \& K. Martens, 2020. Are Cardinium infections causing asexuality in non-marine ostracods? Hydrobiologia. https://doi.org/10.1007/s10750-019-04110-2.

Serpa, K. V., W. P. Kiffer Jr., M. F. Borelli, M. A. Ferraz \& M. S. Moretti, 2020. Niche breadth of invertebrate shredders in tropical forest streams: which taxa have restricted habitat preferences? Hydrobiologia. https://doi.org/10.1007/ s10750-019-04149-1.

WWF. 2018. Living Planet Report - 2018: Aiming Higher. Grooten, M. and Almond, R.E.A. (Eds). WWF, Gland, Switzerland.

Publisher's Note Springer Nature remains neutral with regard to jurisdictional claims in published maps and institutional affiliations. 